\title{
Lag-time in Alzheimer's disease patients: a potential plasmatic oxidative stress marker associated with ApoE4 isoform
}

\author{
Luca Massaccesi ${ }^{1}$, Emanuela Galliera ${ }^{1,2^{*}}$ (D), Daniela Galimberti ${ }^{3,4}$, Chiara Fenoglio ${ }^{3,4}$, Marina Arcaro ${ }^{4}$, Giancarlo Goi ${ }^{5}$,
} Alessandra Barassi ${ }^{6}$ and Massimiliano Marco Corsi Romanelli, ${ }^{1,7}$

\begin{abstract}
In the brain, Oxidative Stress (OS) contribute to structural and functional changes associated with vascular aging, such as endothelial dysfunction, extracellular matrix degradation, resulting in age-related reduced vasodilatation in response to agonists. For this reason, OS is considered a key factor in Alzheimer's Disease (AD) development and recent evidence correlated oxidative stress with vascular lesion in the pathogenesis of $A D$, but the mechanism still need to be fully clarified.

The etiology of $A D$ is still not completely understood and is influenced by several factors including Apolipoprotein E (ApoE) genotype. In particular, the Apo $\varepsilon 4$ isoform is considered a risk factor for AD development.

This study was aimed to evaluate the possible relationship between three plasmatic OS marker and Apo $\varepsilon 4$ carrier status. Plasmatic soluble receptor for advanced glycation end products (sRAGE) levels, plasma antioxidant total defenses (by lag-time method) and plasmatic Reactive Oxygen species (ROS) levels were evaluated in 25 AD patients and in 30 matched controls. ROS were significantly higher while plasma antioxidant total defenses and SRAGE levels were significantly lower in AD patients compared to controls. In AD patients lag-time values show a significant positive linear correlation with SRAGE levels and a (even not significant) negative correlation with ROS levels. Lag-time is significantly lower in $\varepsilon 4$ carrier $(N=13)$ than in $\varepsilon 4$ non-carrier $(N=12)$. Our result confirms the substantial OS in AD. Lag-time levels showed a significant positive correlation with sRAGE levels and a significant association with $\varepsilon 4$ carrier status suggesting that plasmatic lag-time evaluation can be considered as a potential useful OS risk marker in AD.
\end{abstract}

Keywords: Oxidative stress, Vascular dysfunction, Age-associated diseases, Alzheimer's disease

\section{Introduction}

Alzheimer disease (AD) accounts for the largest proportion of dementia diseases in the older population [1]. Recent evidences indicated that vascular dysfunction and damage are linked to cerebrovascular disorders in the elderly and increase significantly AD incidence [2]. The vascular endothelium is a major target of oxidative stress (OS) caused by Reactive Oxygen species (ROS), which play a critical role in the pathophysiology of vascular disease. ROS are important regulators of the

\footnotetext{
* Correspondence: emanuela.galliera@unimi.it

${ }^{1}$ Department of Biomedical Sciences for Health, Università degli Studi di Milano, Milan, Italy

${ }^{2}$ IRCCS Galeazzi Orthopaedic Institute, Milan, Italy

Full list of author information is available at the end of the article
}

inflammatory response: on one hand, at low concentration they act as regulators of cell growth and activity in the inflammatory process, on the other hand, at high concentration they have deleterious effects on cells and tissues [3]. The oxidative stress results from an imbalance between ROS and antioxidant molecules, resulting in an excess of ROS leading to cell injury and death and it is commonly associated with ageing process and age-related degenerative disorders [4]. Compared to other organs, the brain is more vulnerable to oxidative stress due to its high rate of oxygen consumption [4]. In the brain, OS also contribute to structural and functional changes associated with vascular aging, such as endothelial dysfunction, extracellular matrix degradation, resulting in age-related reduced vasodilatation in response to agonists [5]. For this

(c) The Author(s). 2019 Open Access This article is distributed under the terms of the Creative Commons Attribution 4.0 International License (http://creativecommons.org/licenses/by/4.0/), which permits unrestricted use, distribution, and reproduction in any medium, provided you give appropriate credit to the original author(s) and the source, provide a link to the Creative Commons license, and indicate if changes were made. The Creative Commons Public Domain Dedication waiver (http://creativecommons.org/publicdomain/zero/1.0/) applies to the data made available in this article, unless otherwise stated. 
reason $\mathrm{OS}$ is considered a key factor in $\mathrm{AD}$ development since asymptomatic stages [6-8]. Recent evidences correlated oxidative stress with vascular lesions in the pathogenesis of $\mathrm{AD}$, but the mechanism still need to be fully clarified.

The etiology of AD is still not completely understood and is influenced by several factors including Apo lipoprotein E (ApoE) genotype [9], considered an important risk factor for $\mathrm{AD}$. In particular, ApoE exists in three isoform (ApoE2, ApoE3 and ApoE4) but the risk for AD development strongly increases only in the ApoE4 ( $\varepsilon 4$ ) carriers [10]. The aim of this study is to measure plasmatic OS markers in AD patients to evaluate the possible role of OS biomarkers as noninvasive blood-based tool to evaluate $\mathrm{AD}$ diagnostic and monitoring. In addition, plasmatic OS markers will be evaluated in ApoE4 ( $\varepsilon 4)$ carrier and not carrier AD patients, in order to identify a possible correlation with ApoE4 ( $(\varepsilon 4)$ status and define a potential profile of risk factors for $\mathrm{AD}$ development.

\section{Material and methods}

\section{Subjects}

Twenty-five patients with Alzheimer's Disease (AD), aged $74.0 \pm 6.34$; including $13 \varepsilon 4$ carrier and $12 \varepsilon 4$ non-carrier, were recruited from UOSD Neurologia-Malattie Neurodegenerative, Fondazione IRCCS $\mathrm{Ca}^{\prime}$ Granda Ospedale Maggiore Policlinico, Milan, Italy. The control group was composed by 30 adult volunteer blood donors, aged 75.36 \pm 10.71 , from the Italian Association of Blood Volunteers (AVIS) in Milan, Italy. The study was carried out in accordance with recommendation of ethical committee of Fondazione IRCCS Ca' Granda Ospedale Maggiore Policlinico (approval number: 441/2016) All subjects gave written informed consent in accordance with the Declaration of Helsinki.

\section{Materials}

Commercial chemicals were of the highest available grade. The water routinely used was freshly redistilled in a glass apparatus. Copper (II) sulphate $\left(\mathrm{CuSO}_{4}\right)$, was purchased from Sigma Chemical Co. (St. Louis, MO, USA). All other reagents were purchased from Merck (Darmstad, Germany). D-ROMs kit test was purchased from Diacron International (Grosseto, Italy).

\section{Blood samples and serum/plasma preparation}

Plasma was prepared from heparinized venous blood. After collection, blood samples were immediately centrifuged for $15 \mathrm{~min}$ at $3000 \times \mathrm{g}$ and plasma immediately withdrawn and stored at $-20{ }^{\circ} \mathrm{C}$ until ELISA assay and evaluation of plasmatic oxidative status.

\section{Evaluation of plasma oxidative status}

Plasma lipid hydroperoxide levels (ROS) were determined colorimetrically according to Trotti et al. [11] and expressed as $\mathrm{H}_{2} \mathrm{O}_{2}$ equivalents.

The kinetics of plasma oxidation, induced by addition of $\mathrm{CuSO}_{4} 0.5 \mathrm{M}$, were determined at $37^{\circ} \mathrm{C}$ by monitoring the development of fluorescence at $430 \mathrm{~nm}$, setting the excitation at $355 \mathrm{~nm}$ as described by Cervato et al. [12] by Multilabel Counter Wallac 1420 from PerkinElmer. This method allows the evaluation of the peroxidation kinetics monitored following the formation of fluorescent adducts originating from the reaction of aldehydes (derived from lipid peroxidation promoted by $\mathrm{Cu}++$ bound to apolipoproteins) with amino groups of plasma proteins and/or phospholipids. The kinetic is expressed by a sigmoid curve that can be divided into an initial latency phase, followed by a second propagation phase. The initial latency phase (lag time, expressed in minutes and calculated as the intercept of the linear regression of the propagation phase with that of the latency phase) is an index of lipoprotein resistance to peroxidation.

\section{SRAGE ELISA assay}

Levels of soluble RAGE (Receptor of Activated Glycoslation Endproducts) in plasma were determined by ELISA commercial assays, according to the manufacturers' instructions (sRAGE: R\&D Systems, Minneapolis, Minnesota, USA). For the sRAGE assay, the sensitivity was $4.44 \mathrm{pg} / \mathrm{mL}$, and intra- and inter-assay coefficients of variation were 2.4 and $4.7 \%$, respectively.

\section{Statistical analysis}

The Shapiro-Wilk test showed no significative difference from normal distribution. Therefore, parametric techniques were used. Means were compared by Student t-test. The Pearson correlation coefficient $\left(r^{2}\right)$ was calculated to determine the correlation between values measured by different assays. Distribution and correlation analysis were performed using the SPSS STATISTIC 25 package (SPSS Inc., Chicago, IL, USA).

\section{Results}

Plasma peroxidation parameters.

ROS were significantly higher $(P<0,01)$ in AD patients compared to controls, while plasma antioxidant total defenses (measured by lag time) and sRAGE levels were significantly lower $(P<0,001)$ in AD patients compared to controls (Fig. 1).

In $\mathrm{AD}$ patients lag-time values show a significant $(P<0,05)$ positive linear correlation with sRAGE levels and a negative correlation, even though not significant, with ROS levels (Fig. 2).

Evaluation of OS according to ApoE4 \&4 carrier status. 


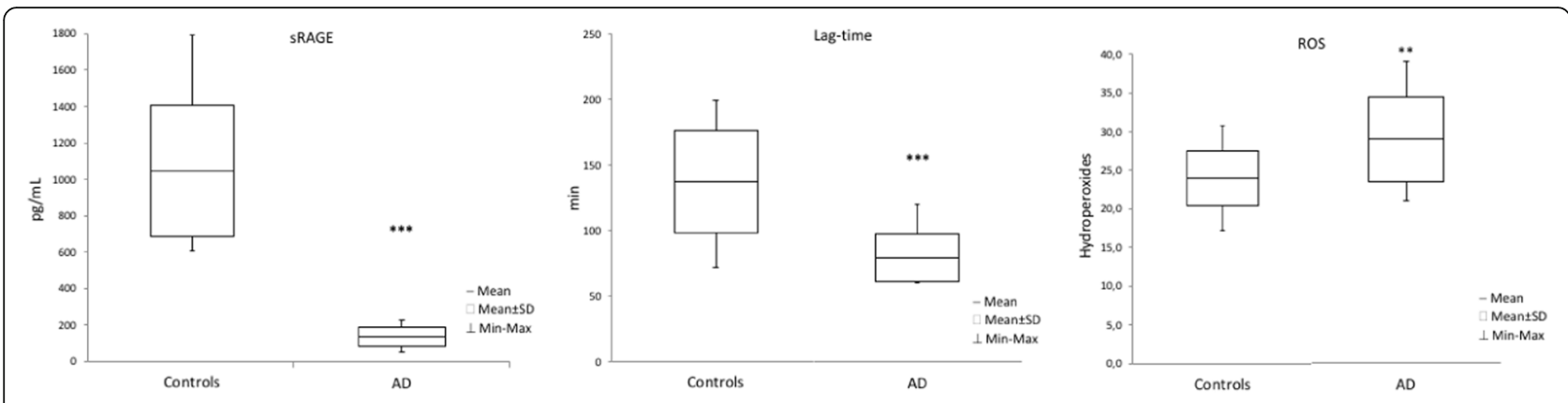

Fig. 1 Plasma peroxidation parameters. The following parameters was measured in AD jj patients and controls: Soluble RAGe (sRAGE, pg/mL), Lag Time (min) and ROS (Hydroperoxides). Hydroperoxides are expressed as equivalent of $\mathrm{H}_{2} \mathrm{O}_{2} \mathrm{mg} / \mathrm{dL}$ of plasma. Results are expressed ad mean \pm SD. ** $P<0.01 * * * P<0.001$ controls versus AD subjects

Lag-time is significantly lower $(P<0,05)$ in $\varepsilon 4$ carrier than in $\varepsilon 4$ non-carrier (Fig. 3).

\section{Discussion}

The brain is the most metabolically active organ in the human body and requires around the $20 \%$ of the whole organism's energy. There are increasing evidences that a failure in the ability to maintain a well-balanced ROS level causes cerebrovascular dysfunction, which promotes an increase in blood-brainbarrier (BBB) leakage interfering with brain energy supply and homeostasis and increasing amyloid $\beta(A \beta)$ peptide deposition in vascular walls [13]. Alterations in $\mathrm{BBB}$ features are associated with oxidative stress and inflammatory processes, leading to neurodegenerative conditions resulting in a decline of cerebrovascular function, typical of age-associated diseases, such as $\mathrm{AD}[8,13,14]$.

It was demonstrated that the risk for $\mathrm{AD}$ is strongly increased in the ApoE4 ( $\varepsilon 4)$ carriers [10] and that the occurrence of OS in neurological disorders as mild cognitive impairment $(\mathrm{MCI})$ could be related to $\varepsilon 4$ carrier status [15].
In our study we have evaluated in $\mathrm{AD}$ patients, both in ApoE4 ( $\varepsilon 4)$ carriers and non-carriers, three plasmatic OS markers (Plasmatic soluble receptor for advanced glycation end products - sRAGE - levels, plasma antioxidant total defenses, by lag-time method, and plasmatic ROS levels in order to evaluate a possible association between these OS markers and ApoE4 ( $\varepsilon 4)$ carrier status.

To evaluate the antioxidant defenses in vivo we evaluated the total "oxidation resistance" of plasma lipoproteins using the fluorescent kinetics method of Lag-time $[12,16]$ that provides a comprehensive picture of plasma susceptibility to peroxidation in comparison with the conventional measurements of antioxidant and pro-oxidant ratios, including the antioxidant enzyme activities [17].

Several studies in literature reports showed an increase of OS markers in $\mathrm{AD}$ patients, confirming the strong relation between $\mathrm{OS}$ and $\mathrm{AD}[5,18-20]$. In addition, the presence of oxidative stress markers such as advanced glycation End Product (AGE) has been detected in AD patients $[4,21,22]$. Consistently, we observed a significative increase of ROS in AD patients, associated with a significative decrease in antioxidant defense, measured
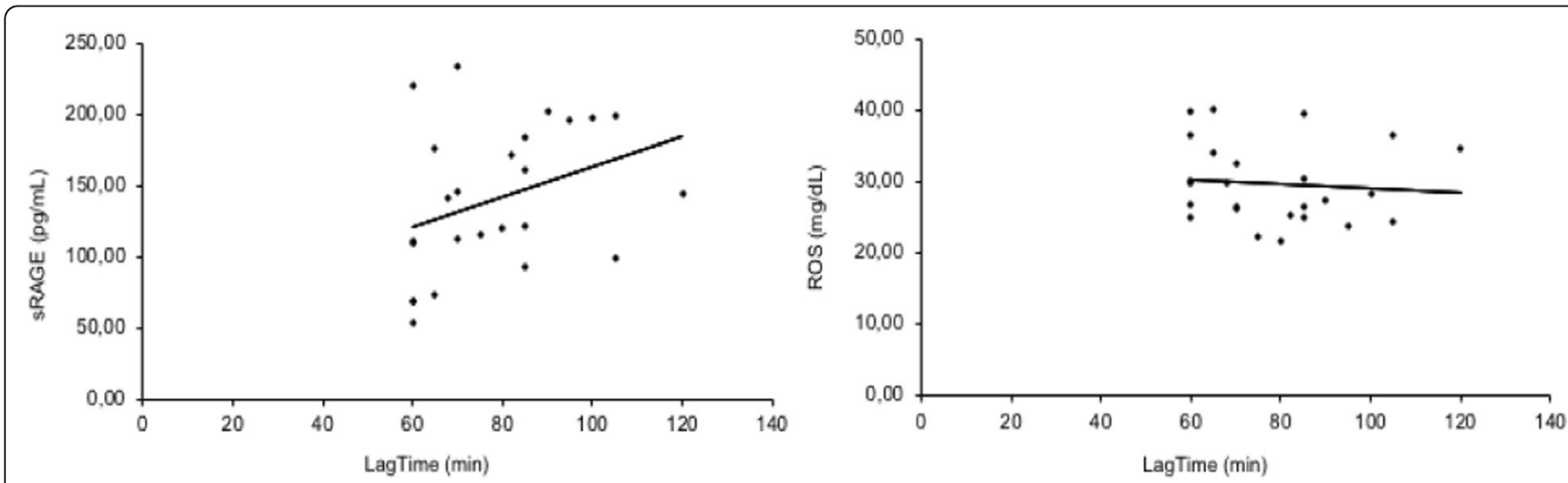

Fig. 2 Correlation analysis between lag time and others oxidative parameters in AD patients. Lag-time values show a significant $(p<0,05)$ positive linear correlation $\left(r^{2}=0,347\right)$ with sRAGE levels $(\mathrm{ng} / \mathrm{mL})$ and a (even not significant) negative correlation $\left(r^{2}=-0,101\right)$ with ROS (mg/dL) levels 


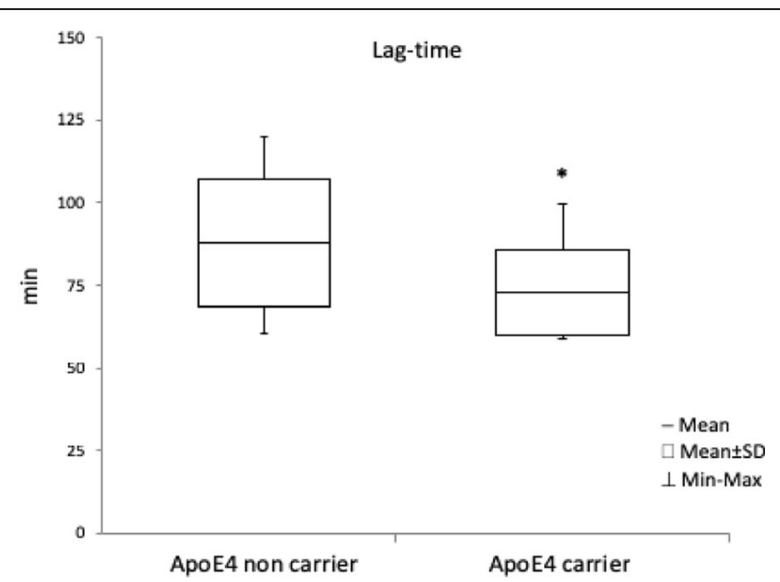

Fig. 3 Variation of plasma peroxidation parameter in ApoE4 carrier. Variation of plasma peroxidation parameter (Lag Time) was evaluated in ApoE4 carrier $(N=13)$ compared to ApoE4 non carrier $(N=12)$. Results are expressed ad Mean \pm SD $* \quad<0.05$ e4 carrier versus e4 non-carrier

by lag time and significative decrease of the soluble AGE receptor sRAGE. sRAGE have been extensively studied as protective factor against AGE induced cell damage [23-26]. Indeed, soluble receptor for AGE (sRAGE) counteracts the adverse effects of AGE-RAGE interaction by competing with RAGE for binding with AGE and low levels of serum sRAGE have been proposed as a biomarker for diseases, including AD [25]. In our study, sRAGE also showed a significative correlation with the other two biomarkers of oxidative stress, lag time and ROS, confirming that in $\mathrm{AD}$ patient's sRAGE can be considered a useful tool to evaluate OS status, along with ROS and lag time. Many end-products of peroxidation have been identified in the brain tissue and in blood circulation of $\mathrm{AD}$ patients suggesting that $\mathrm{OS}$ biomarkers could represent useful tools for noninvasive blood-based $\mathrm{AD}$ diagnostic and monitoring. Considering that the ideal biomarker should be not only rapid, reproducible, easy to perform but also less invasive as possible, in particular in the elderly, the plasmatic OS determination in AD clinical practice is getting an increasing importance [27, 28]. A first correlation between carrier and OS biomarkers in neurodegenerative disease was suggested in mild cognitive impairment (MCI) where a positive correlation was observed between superoxide dismutase activity and $\mathrm{MCI}$ [29], and in the neurodegenerative aspects of $\mathrm{AD}$ [30, 31]. Previous evidences showed a specific pattern, characterized by higher tHcy and lower TAC levels, was observed in $A D$, indicating that oxidative imbalance seems to play a role in the pathogenesis of $\mathrm{AD}$ [32]. In addition, Miyata and Smith [33] showed that ApoE has allele-specific beneficial effect against free radicals reducing neuronal death due to hydrogen peroxide and beta-amyloid through antioxidant activity. This protective effect is detectable with the E2 isoform but tends to vanish with E3 isoform and almost disappear with $\mathrm{E} 4$ isoform, indicating that the ApoE4 ( $\varepsilon 4)$ isoform lack the antioxidant protective activity and is more prone to OS damage [34, 35].

According to all these evidences our data showed a consistent OS condition in the AD patients with an intriguing result regarding plasma antioxidant total defenses (lag-time).

Lag-time method allows a complete evaluation of the total plasmatic antioxidant defenses in vivo in comparison with the conventional measurements of pro-oxidant markers. Indeed, despite a practically equivalent OS levels in e4 carrier and not carrier (as pointed out from ROSs and sRage values), lag-time results to be significantly lower in the e4 carrier subject. Indeed, this parameter resulted significantly lower in the ApoE4 ( $\varepsilon 4)$ carriers in comparison to the not carrier suggesting a significant decrease of antioxidant defenses in these subjects, consistently with a previous work in a murine model by Myata and Smith showing, in a murine model, the decrease of the antioxidants activities due to the presence of the allele ApoE4 [33] (ع4).

Taken together these results indicated that Lag-time levels, as measure of antioxidant defenses, shown a significant decrease in $\mathrm{APO} \varepsilon 4$ carrier and a positive correlation with the decrease of the protective factor sRAGE levels.

\section{Conclusion}

Our results confirm the substantial OS in AD. Lag-time levels, as measure of antioxidant defenses, showed a positive correlation with ApoE4 ( $\varepsilon 4)$ carrier status and sRAGE, suggesting that plasmatic lag-time evaluation can be considered as a useful OS marker for monitoring $\mathrm{AD}$ patients and as a further potential risk marker for $\mathrm{AD}$ development.

\section{Abbreviations}

AD: Alzheimer's Disease; ApoE: Apolipoprotein E; OS: Oxidative Stress; ROS: Reactive Oxygen Species; SRAGE: soluble Receptor for Advanced Glycation End-products

\section{Acknowledgements}

Not applicant.

\section{Funding}

This study was supported by Ricerca Corrente funding by Ministry of Health to IRCCS, Policlinico San Donato.

\section{Availability of data and materials}

The dataset generated and /or analysed during the current study are not publicly available due to patients' privacy but are partially available from the corresponding author on reasonable request.

\section{Authors' contributions}

LM and EG contributed conception and design of the study, LM performed the oxidative stress evaluation, GG and MMCR revised critically data interpretation, DG CF and MA performed patient's enrollment and sample collection, LM and EG wrote the draft of the manuscript. All authors contributed to manuscript revision, read and approved the submitted version. 


\section{Ethics approval and consent to participate}

The study was carried out in accordance with recommendation of ethical committee of Fondazione IRCCS Ca' Granda Ospedale Maggiore Policlinico (approval number: 441/2016) All subjects gave written informed consent in accordance with the Declaration of Helsinki.

\section{Consent for publication}

Not applicable.

\section{Competing interests}

The authors declare that they have no competing interests.

\section{Publisher's Note}

Springer Nature remains neutral with regard to jurisdictional claims in published maps and institutional affiliations.

\begin{abstract}
Author details
${ }^{1}$ Department of Biomedical Sciences for Health, Università degli Studi di Milano, Milan, Italy. ${ }^{2}$ IRCCS Galeazzi Orthopaedic Institute, Milan, Italy. ${ }^{3}$ Department of Pathophysiology and Transplantation, Università degli Stud di Milano, Centro "Dino Ferrari", Milan, Italy. ${ }^{4}$ U.O.S.D. Neurologia-Malattie Neurodegenerative, Fondazione IRCCS Ca' Granda Ospedale Maggiore Policlinico, Milan, Italy. ${ }^{5}$ Department of Biomedical, Surgical and Dental Sciences, Università degli Studi di Milano, Milan, Italy. ${ }^{6}$ Department of Health's Science, Università degli Studi di Milano, Milan, Italy. ${ }^{7}$ U.O.C SMEL-1 Patologia Clinica IRCCS Policlinico San Donato, San Donato, Milan, Italy.
\end{abstract}

Received: 17 December 2018 Accepted: 14 March 2019 Published online: 01 April 2019

\section{References}

1. Di Marco LY, Venneri A, Farkas E, Evans PC, Marzo A, Frangi AF. Vascular dysfunction in the pathogenesis of Alzheimer's disease--a review of endothelium-mediated mechanisms and ensuing vicious circles. Neurobiol Dis. 2015 Oct:82:593-606.

2. Kalaria RN. The role of cerebral ischemia in Alzheimer's disease. Neurobiol Aging. 2000 Mar-Apr;21(2):321-30

3. Chen Q, Wang Q, Zhu J, Xiao Q, Zhang L. Reactive oxygen species: key regulators in vascular health and diseases. Br J Pharmacol. 2018 Apr;175(8): 1279-92.

4. Aliev G, Smith MA, Seyidov D, Neal ML, Lamb BT, Nunomura A, et al. The role of oxidative stress in the pathophysiology of cerebrovascular lesions in Alzheimer's disease. Brain Pathol. 2002 Jan;12(1):21-35.

5. Carvalho C, Moreira PI. Oxidative stress: a major player in cerebrovascular alterations associated to neurodegenerative events. Front Physiol. 2018:9:806.

6. Bonet-Costa V, Pomatto LC, Davies KJ. The Proteasome and Oxidative Stress in Alzheimer's Disease. Antioxid Redox Signal. 2016;25(16):886-901. https:// doi.org/10.3389/fphys.2018.00806.

7. Pratico D, Clark CM, Liun F, Rokach J, Lee WY, Trojanowski JQ. Increase of brain oxidative stress in mild cognitive impairment: a possible predictor of Alzheimer disease. Arch Neurol. 2002;59(6):972-6.

8. Zhao $Y$, Zhao B. Oxidative stress and the pathogenesis of Alzheimer's disease. Oxidative Med Cell Longev. 2013:316523. https://doi.org/10.1155/ 2013/316523.

9. Tamaoka A, Miyatake F, Matsuno S, Ishii K, Nagase S, Sahara N, et al. Apolipoprotein E allele-dependent antioxidant activity in brains with Alzheimer's disease. Neurology. 2000 Jun 27;54(12):2319-21.

10. Badia MC, Lloret A, Giraldo E, Dasi F, Olaso G, Alonso MD, et al. Lymphocytes from young healthy persons carrying the ApoE4 allele overexpress stress-related proteins involved in the pathophysiology of Alzheimer's disease. J Alzheimers Dis. 2013;33(1):77-83. https://doi.org/10. 3233/JAD-2012-120973.

11. Trotti R, Carratelli M, Barbieri M, Micieli G, Bosone D, Rondanelli M, et al. Oxidative stress and a thrombophilic condition in alcoholics without severe liver disease. Haematologica. 2001;86(1):85-91.

12. Cervato G, Viani P, Cazzola R, Cestaro B. A fluorescence method for the determination of plasma susceptibility to lipid peroxidation. Clin Biochem. 1999 Apr;32(3):171-7.
13. Wevers NR, de Vries HE. Morphogens and blood-brain barrier function in health and disease. Tissue Barriers. 2015;4(1):e1090524. https://doi.org/10. 1080/21688370.2015.1090524.

14. Lopez N, Tormo C, De Blas I, Llinares I, Alom J. Oxidative stress in Alzheimer's disease and mild cognitive impairment with high sensitivity and specificity. J Alzheimers Dis. 2013;33(3):823-9. https://doi.org/10.3233/JAD2012-121528.

15. Chico L, Simoncini C, Lo Gerfo A, Rocchi A, Petrozzi L, Carlesi C, et al. Oxidative stress and APO E polymorphisms in Alzheimer's disease and in mild cognitive impairment. Free Radic Res. 2013 Aug;47(8):569-76. https:// doi.org/10.3109/10715762.2013.804622

16. Cestaro B, Gandini R, Viani P, Maraffi F, Cervato G, Montalto C, et al. Fluorescence-determined kinetics of plasma high oxidability in diabetic patients. Biochem Mol Biol Int. 1994 Apr;32(5):983-94.

17. Atamer A, Kocyigit $Y$, Ecder SA, Selek S, Ilhan N, Ecder $T$, et al. Effect of oxidative stress on antioxidant enzyme activities, homocysteine and lipoproteins in chronic kidney disease. J Nephrol. 2008 Nov-Dec;21(6): 924-30

18. Cheignon C, Tomas M, Bonnefont-Rousselot D, Faller P, Hureau C, Collin F. Oxidative stress and the amyloid beta peptide in Alzheimer's disease. Redox Biol. 2018 Apr;14:450-64. https://doi.org/10.1016/j.redox.2017.10.014

19. Collin F, Cheignon C, Hureau C. Oxidative stress as a biomarker for Alzheimer's disease. Biomark Med. 2018 Mar;12(3):201-3. https://doi.org/10. 2217/bmm-2017-0456

20. de Leeuw FA, Peeters CFW, Kester MI, Harms AC, Struys EA, Hankemeier T, et al. Blood-based metabolic signatures in Alzheimer's disease. Alzheimers Dement (Amst). 2017;8:196-207. https://doi.org/10.1016/j.dadm.2017.07.006.

21. Markesbery WR. Oxidative stress hypothesis in Alzheimer's disease. Free Radic Biol Med. 1997;23(1):134-47.

22. Drenth H, Zuidema SU, Krijnen WP, Bautmans I, van der Schans C, Hobbelen $\mathrm{H}$. Association between advanced glycation end-products and functional performance in Alzheimer's disease and mixed dementia. Int Psychogeriatr. 2017 Sep;29(9):1525-34. https://doi.org/10.1017/S1041610217000886.

23. Ajith TA, Vinodkumar P. Advanced Glycation end products: association with the pathogenesis of diseases and the current therapeutic advances. Curr Clin Pharmacol. 2016:11(2):118-27.

24. Xie J, Mendez JD, Mendez-Valenzuela V, Aguilar-Hernandez MM. Cellular signalling of the receptor for advanced glycation end products (RAGE). Cell Signal. 2013 Nov;25(11):2185-97. https://doi.org/10.1016/j.cellsig.2013.06.013.

25. Walker D, Lue LF, Paul G, Patel A, Sabbagh MN. Receptor for advanced glycation endproduct modulators: a new therapeutic target in Alzheimer's disease. Expert Opin Investig Drugs. 2015;24(3):393-9. https://doi.org/10. $1517 / 13543784.2015 .1001490$

26. Juranek J, Ray R, Banach M, Rai V. Receptor for advanced glycation endproducts in neurodegenerative diseases. Rev Neurosci. 2015;26(6):691-8. https://doi.org/10.1515/revneuro-2015-0003.

27. Uttara B, Singh AV, Zamboni P, Mahajan RT. Oxidative stress and neurodegenerative diseases: a review of upstream and downstream antioxidant therapeutic options. Curr Neuropharmacol. 2009 Mar;7(1):65-74.

28. Sultana R, Baglioni M, Cecchetti R, Cai J, Klein JB, Bastiani P, et al. Lymphocyte mitochondria: toward identification of peripheral biomarkers in the progression of Alzheimer disease. Free Radic Biol Med. 2013 Dec;65: 595-606. https://doi.org/10.1016/j.freeradbiomed.2013.08.001.

29. Swomley AM, Butterfield DA. Oxidative stress in Alzheimer disease and mild cognitive impairment: evidence from human data provided by redox proteomics. Arch Toxicol. 2015 Oct;89(10):1669-80. https://doi.org/10.1007/ s00204-015-1556-z.

30. Garcia-Blanco A, Baquero M, Vento M, Gil E, Bataller L, Chafer-Pericas C. Potential oxidative stress biomarkers of mild cognitive impairment due to Alzheimer disease. J Neurol Sci. 2017 Feb 15;373:295-302. https://doi.org/10. 1016/j.jns.2017.01.020.

31. Kamat PK, Kalani A, Rai S, Swarnkar S, Tota S, Nath C, et al. Mechanism of oxidative stress and synapse dysfunction in the pathogenesis of Alzheimer's disease: understanding the therapeutics strategies. Mol Neurobiol. 2016 Jan; 53(1):648-61. https://doi.org/10.1007/s12035-014-9053-6.

32. Guidi I, Galimberti D, Lonati S, Novembrino C, Bamonti F, Tiriticco M, et al. Oxidative imbalance in patients with mild cognitive impairment and Alzheimer's disease. Neurobiol Aging. 2006 Feb;27(2):262-9.

33. Miyata M, Smith JD. Apolipoprotein E allele-specific antioxidant activity and effects on cytotoxicity by oxidative insults and beta-amyloid peptides. Nat Genet. 1996 Sep;14(1):55-61. 
34. Ramassamy C, Averill D, Beffert U, Bastianetto S, Theroux L, Lussier-Cacan S, et al. Oxidative damage and protection by antioxidants in the frontal cortex of Alzheimer's disease is related to the apolipoprotein E genotype. Free Radic Biol Med. 1999 Sep;27(5-6):544-53.

35. Ramassamy C, Averill D, Beffert U, Theroux L, Lussier-Cacan S, Cohn JS, et al. Oxidative insults are associated with apolipoprotein $\mathrm{E}$ genotype in Alzheimer's disease brain. Neurobiol Dis. 2000 Feb;7(1):23-37.

Ready to submit your research? Choose BMC and benefit from:

- fast, convenient online submission

- thorough peer review by experienced researchers in your field

- rapid publication on acceptance

- support for research data, including large and complex data types

- gold Open Access which fosters wider collaboration and increased citations

- maximum visibility for your research: over $100 \mathrm{M}$ website views per year

At BMC, research is always in progress.

Learn more biomedcentral.com/submissions 